Original Article

\title{
A STUDY TO DETERM INE THE EFFECTIVENESS OF AN AWARENESS PROGRAMME ON KNOWLEDGE ON SUBSTANCE ABUSE AND ITS CONSEQUENCES AM ONG THE STUDENTS OF A SELECTED PRE UNIVERSITY COLLEGE OF UDUPI DISTRICT, KARNATAKA
}

\author{
Charis Theou I I ${ }^{1}$ Asha K Nayak ${ }^{2} \&$ Tessy Treesa Jose ${ }^{3}$ \\ ${ }^{1}$ Post Graduate, ${ }^{2}$ Assistant Professor, ${ }^{3}$ Professor \& HOD, Department of Psychiatric Nursing, \\ Manipal College of Nursing Manipal, Manipal University, Manipal, Karnataka. \\ Correspondence : \\ Charis Theou \\ Post Graduate, Department of Psychiatric Nursing M anipal College of Nursing M anipal, Manipal University, \\ Manipal - 576 014, Karnataka, India. \\ Mobile : +91 8867596464 E-mail : charistheou.i@gmail.com
}

\begin{abstract}
:
Background : Adolescence is a fluctuating period wherein they love to do things as they wish and something that gives them a thrill without reasoning and hencethey need to be guided.

Objective : Determine the knowledge and find the effectiveness of an awareness program on substance abuse and its consequences among the PU Collegestudents.

Find the association between the pretest knowledge scores and the selected variables like age, gender, monthly income of parents, and education of parents, birth order and history of substance abuse in the family.

Method : A Pre-test post-test design was used. Fifty three students from Udupi district was selected by convenient sampling. The tool used was knowledge questionnaire on substance abuse and its consequences. Demographic proforma was used to collect the background information. SPSS software version 16 wasused for data analysis.

Results : Pretest knowledge shows that $91 \%$ of the students had average knowledge and about $2 \%$ of the students had poor knowledge whereas only $7 \%$ had good knowledge. The post-test result shows that $28(52.8 \%)$ students had good knowledge on substance abuse and its consequences. The indices show a steady increase in knowledge from $7.5 \%$ during the pre-test to $52.8 \%$ during the posttest with a mean difference of 4.23 between pre-test and post-test at 0.05 level of significance $(p>0.001)$
\end{abstract}

Conclusion : Awareness programme helps students to gain knowledge and helps in enlightening their future.

Keywords: awareness programme, knowledge, substance abuse.

\section{Introduction:}

Adolescence is a fluctuating period wherein there is total confusion regarding everything that is supposed to be performed. It is a period wherein the adolescentslove to be popular among all their peers and ready to do things as they wish and something Access this article online Quick Response Code

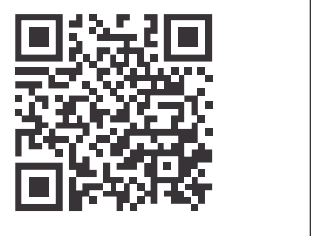
that gives them a thrill. They have their own social grouping, new values in selection of friends and social acceptance etc.

Presently we have lot of addicts in our country who use them as a daily routine and are spreading rapidly like fire. Drug addiction is spreading like a contagious disease in the world and India cannot escape from its clutches and people are subjected to greater stress and strains as a result of the rapid change in the life style. The drug situation in India has acquired a serious dimension. India is no longer merely a country for the transit of Illicit drugs from the Golden Triangle or Golden Crescent, but it is fast becoming a potential market for its consumption. ${ }^{1}$

Various studies on substance abuse are being carried out because of the various reasons. A study carried out by the ministry of social justice and empowerment revealed that 
the rate of prevalence for various substance among the age group 12-18 was highest for which alcohol was $21.4 \%$ and the next prevalent was Cannabis with 3\%, drugs of Opiate origin $0.7 \%$ and other illicit drugs were $3.6 \%$. Apart from this, the study also surveyed the people who are at high risk and they were workers at transport, sex workers and children in the streets. ${ }^{2}$

A survey was conducted by the ministry of health in 14 cities of India on drug abuse. A total of 4648 members were surveyed among which 371 women abused drugs which totals up to $8 \%$ of them. Both men and women abused cannabis i.e. $40 \%$, among the rest $33 \%$ used alcohol, $6 \%$ used sedatives and tranquillizers, $5 \%$ heroin, $5 \%$ painkillers, $5 \%$ opioids and $1 \%$ inhalants. $^{3}$

The report given by M inistry of Health and Family Welfare revealed that in Delhi alone, 20 times increase in the sale and production was noted on Indian Made Foreign Liquor between 1982 and 1988. As a result, drinking members in the family increased leaving nearly 5 million addicts. The revenue from liquor was Rs.50 crore at the time of Independence and presently Rs.12,000 crore per year, every year Rs.60,000 crore goes for illicit liquor alone. Kerala stands first today in the consumption of liquor (8.3 liters) followed by Punjab (7.9 liters) against the National average of 5.7 liters. A survey conducted jointly by WHO and Alcohol and Drug information Center among the college students in Kerala found that the age at which they consumed liquor for first time is coming down from 19 in 1986,17 in 1990 and 14 in $1994 .{ }^{4}$

A study conducted by Gincy in Mangalore University Colleges among 15,000 students showed that $0.4 \%$ of females and $7.04 \%$ of males have used substances varying from Ganja to Heroin. Among them, $0.4 \%$ of the females and $6.6 \%$ of the males were drug addicts. It also revealed that among 15,000 students under study 1050 students were addicts.

\section{Purpose of the study}

Thus keeping into consideration the various different consequences that can be caused to the students who knowingly or unknowingly get trapped into the clutches of substance abuse the study is undertaken among the PU College students in order to guide them to choose the right path and make our nation a better place to live in.

\section{Objectives:}

1. Determine the knowledge and find the effectiveness of an awareness program on substance abuse and its consequences among the PU College students.

2. Find the association between the pretest knowledge scores and the selected variables like age, gender, monthly income of parents, and education of parents, birth order and history of substance abuse in the family.

\section{Hypothesis:}

1. $\mathbf{H}_{1}$ : There will be a significant difference between the pre-test and post-test knowledge scores on substance use and its consequences among PU College students.

2. $\mathbf{H}_{2}$ : There will be a significant association between the pretest knowledge scores of PU College students on substance abuse and the selected variables.

\section{Materials and methods:}

The present study aimed at determining the effectiveness of an awareness programme on knowledge of substance abuse and its consequences among the students of selected PU College. Therefore an evaluative approach was adopted. The design selected for the study was one group pretest posttest design. The study was conducted in English medium PU College in Udupi Taluk, Karnataka. The sample size was calculated based on the pilot study findings and estimated sample size was 51 . Total samples present in the study were 53 . The samples were conveniently selected from $2^{\text {nd }}$ PUC, B section. Ethical clearance was taken from the Dean of Manipal College of Nursing Manipal, Institutional ethical committee of Kasturba Hospital, Principal of the selected College and informed consent from the participants.

The instruments used for the study were Demographic proforma which had 10 items designed to gather the background information of the subjects like age in years, gender, monthly income of parents in rupees, education of 
father, education of mother, birth order, history of substance abuse in the family, religion, place of residence and the type of family. A tool on knowledge questionnaire on substance abuse and its consequences was used. The items were constructed after reviewing the research and non-research literature. A blue print was made and based on blue print, items were constructed. Content areas included were meaning of substance abuse, causes of substance abuse, and consequences of selected substances, treatment and rehabilitation of the substance abusers. The knowledge score were arbitrarily categorized into poor $=0-9$, moderate $=10-18$, good $=19-26$. The maximum possible score was 26 .

To establish the content validity of the tool, the constructed tools were submitted to seven experts. The experts were selected on the basis of their clinical expertise, experience and interest in the problem being studied. Two experts were from the field of psychiatry, two from psychiatry social work, one from psychiatric nursing, and two from community health nursing. The experts evaluated each item in terms of its relevancy, adequacy and appropriateness. All the items in the demographic proforma had $100 \%$ agreement and were retained as they were. A tool on knowledge on substance abuse and its consequences having 40 questions were given for validation and depending on the suggestions and opinion of the experts, some items were modified and a total of 26 questions were included for the study. The split half method using spearman brown prophecy formula was used to calculate the reliability of the knowledge questionnaire among 20 students. The reliability coefficient of the tool was $(r=0.805)$. The tool was found to be reliable.

The content of the awareness programme on substance abuse and its consequences was developed based on the literature review and opinion from the experts. The content validity was established. The areas included in the awareness programme were meaning of substance abuse, causes of substance abuse, and consequences of selected substances, treatment and rehabilitation of the substance abuser. The awareness programme was conducted to the group of students which had lecture, discussion and an video on substance abuse and its consequences. The session was conducted by using Power Point slides.

The pilot study was conducted among twelve PU College students. On day one, the demographic proforma and a knowledge questionnaire on substance abuse and its consequences were administered. An awareness programme on substance abuse and its consequences was given on the same day. On eight day, the post test was conducted by administering the same questionnaire on substance abuse and its consequences.

The SPSS statistical package (16 version) was used for analysis of the data. Descriptive statistics (frequency and percentage) were used to describe the sample characteristics and inferential statistics (paired sample't' test) were used to determine the effectiveness of the awareness programme. The significance between the pretest and post-test knowledge score is computed with the paired sample't' test which requires normal distribution. The Shapiro wilktest was done to test the normality.

\section{Results:}

The table 1 describes the sample characteristics in terms of frequency and percentage of 53 students. Out of 53 students, females were 35 (66\%). Majority of them were 17years old. Majority of samples i.e. 23(43.4\%) students family income was $>20,001$ Rupees. The fathers' education was graduation for $28(52.8 \%)$ students and mothers education was higher secondary for 21 (39.6\%) samples.

\section{Knowledge and effectiveness of an awareness programme on substance abuse and its consequences among the PU College students.}

Figure 1 indicates that majority of the studentsi.e. $90.6 \%$ of the students had average knowledge, $1.9 \%$ of the students had poor knowledge whereas only $7.5 \%$ had good knowledge on substance abuse and its consequences.

Figure 2 indicates that among 53 samples, 4 (7.5 \%) had good knowledge during the pre-test. Twenty eight (52.8\%) 
of the samples had good knowledge after the intervention.

The indices show a steady increase in the knowledge from $7.5 \%$ during the pre-test to $52.8 \%$ during the post test.

The significance between the pre-test and post-test knowledge score was computed with the paired sample't' test which requires normal distribution. The Shapiro wilks test was done to test the normality. This test shows that the samples are normally distributed.

The data presented in the table 2 show that the obtained't 'value is 11.36 which is significant at 0.05 level. Hence the awareness programme was an effective method to increase the level of knowledge among the PU College students.

\section{Association between the pre-test knowledge scores on knowledge on substance abuse and its consequences and the selected variables.}

The findings of the study revealed that the computed chi square values for each variables were age $\left(?_{(4)}^{2}=5.379 \mathrm{p}\right.$ $\varangle 0.252)$, gender $\left(?_{(2)}^{2}=0.703, p \varangle 0.599\right)$, monthly income $\left(?^{2}{ }_{44)}=1.982, p \varangle 0.675\right)$, education of father $\left(?^{2}{ }_{(4)}=15.01\right.$, $p<0.301)$, education of mother $\left(?^{2}{ }_{66}=9.351, p \varangle 0.283\right)$, birth order $\left(?^{2}{ }_{44}=5.141 \mathrm{p} \varangle 0.135\right)$, history of substance abuse in the family $\left(?^{2}{ }_{(2)}=4.866, p<0.085\right)$, religion $\left(?^{2}{ }_{(4)}=2.385\right.$ $p<0.677)$, place of residence $\left(?^{2}{ }_{(4)}=3.053, p<0.531\right)$ and type of family was $\left(?_{(2)}^{2}=0.981, p \varangle 0.422\right)$. All the above variables were not found to be statistically significant at 0.05 level of significance. Hence it was inferred that the present knowledge was independent of all the selected variables.

1. Karnool R. A study to assess the effectiveness of structured teaching programme (STP) on knowledge of engineering college students regarding drug addiction in selected engineering colleges at Bangalore. 2013

Table 1: Frequency and percentage distribution of sample characteristics.

$\mathrm{n}=53$

\begin{tabular}{lcc}
\hline Sample characteristics & Frequency(f) & Percentage(\%) \\
\hline Birth order & & \\
First & 28 & 52.8 \\
Second & 22 & 41.5 \\
Third & 03 & 05.7
\end{tabular}

\begin{tabular}{|c|c|c|}
\hline Sample characteristics & Frequency(f) & Percentage(\%) \\
\hline \multicolumn{3}{|c|}{ History of substance abuse in family } \\
\hline Yes & 11 & 20.8 \\
\hline No & 42 & 79.2 \\
\hline \multicolumn{3}{|l|}{ Religion } \\
\hline Christian & 04 & 07.5 \\
\hline Hindu & 44 & 83.0 \\
\hline Muslim & 05 & 09.4 \\
\hline \multicolumn{3}{|l|}{ Place of residence } \\
\hline Rural & 17 & 32.1 \\
\hline Urban & 24 & 45.3 \\
\hline Semi urban & 12 & 22.6 \\
\hline \multicolumn{3}{|l|}{ Type of family } \\
\hline Nuclear & 45 & 84.9 \\
\hline Joint & 08 & 15.1 \\
\hline
\end{tabular}

Table 2: Mean and ' $p$ ' value of the pre-test and post-test knowledge scores of PU College on substance abuse and its consequences.

$(n=53)$

\begin{tabular}{lcccccc}
\hline & Mean SD & $\begin{array}{c}\text { Mean } \\
\text { difference }\end{array}$ & $\begin{array}{c}\text { SD } \\
\text { difference }\end{array}$ & $\begin{array}{c}\text { 't' } \\
\text { pvalue } \\
\text { value }\end{array}$ \\
\hline Pre-test & 14.24 & 2.41 & 4.23 & 0.45 & 11.36 & $<0.001$ \\
Post-test & 18.47 & 2.86 & & & & \\
\hline$p \varangle 0.05$ & & & & & &
\end{tabular}

Figure 1: Pie diagram showing Knowledge of PU college students on substance abuse and its consequences. $n=53$

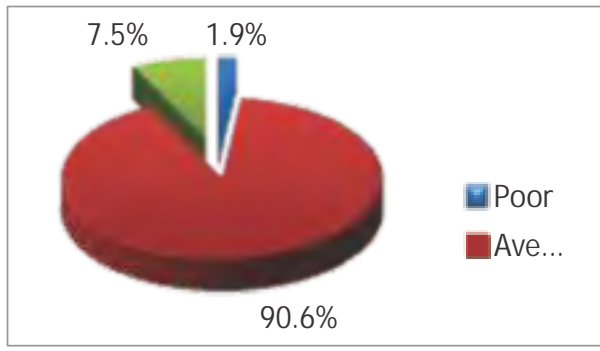

Figure 2 : Bar diagram on comparison between pre-test and post knowledge score of PU college students on substance abuse and its consequences Effectiveness of awareness programme on substance abuse and its consequences $n=53$

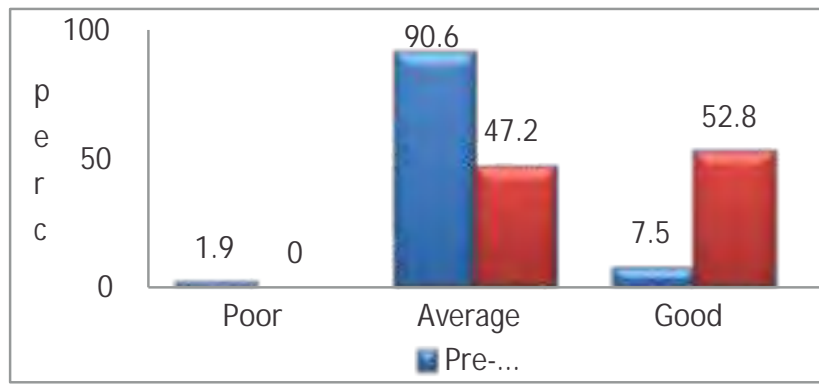

\section{Discussion :}

This study reveals that $90.6 \%$ of the students had average knowledge and $1.9 \%$ of the students had poor knowledge whereas only $7.5 \%$ had good knowledge. The findings of 
the present study is supported by a study conducted in Sikkim on the effectiveness of an awareness programme on substance abuse and its consequences among the adolescents in a selected coaching center. It was revealed that $56 \%$ of the students in the pretest had good knowledge and $48 \%$ had average knowledge. ${ }^{5}$ Present study also supports a study conducted on knowledge of psychoactive substance use among secondary school students in Dodoma which reported that majority of the participants i.e. 399 (99.3\%) had knowledge on definition and types of psychoactive substances. Ninety eight percentage of the participants were knowledgeable on the effects of psychoactive substances and 42(10.4\%) were aware of the places where the psychoactive substances can be found. ${ }^{6}$ Another survey conducted on substance use among adolescent high school st 